\title{
QUALIDADE DE VIDA DE PORTADORES DE FERIDA CRÔNICA
}

\section{Quality of life of chronic wound carriers}

\author{
Patrícia Moita Garcia Kawakame \\ Universidade Federal de Mato Grosso do Sul - UFMS - Campo Grande (MS) - Brasil \\ Luciana Contrera \\ Universidade Federal de Mato Grosso do Sul - UFMS - Campo Grande (MS) - Brasil \\ Thaís Garcia Ferrari \\ Fundação Educacional de Fernandópolis - FEF - Fernandópolis (SP) - Brasil
}

Anna Carolina Furlanetto Novais

Fundação Educacional de Fernandópolis - FEF - Fernandópolis (SP) - Brasil

Jaqueline Fava Santana de Carvalho

Fundação Educacional de Fernandópolis - FEF - Fernandópolis (SP) - Brasil

Juliana Cristina Gobbo

Fundação Educacional de Fernandópolis - FEF - Fernandópolis (SP) - Brasil

Laura Carolina Toledo Mariano de Souza
Fundação Educacional de Fernandópolis - FEF - Fernandópolis (SP) - Brasil

RESUMO

Objetivo: Compreender a qualidade de vida de portadores de ferida crônica. Métodos: Pesquisa qualitativa, na modalidade da análise da estrutura do fenômeno situado, que se fundamenta na Fenomenologia. Os dados foram coletados pelas pesquisadoras por meio de uma questão norteadora direcionada a dez portadores de ferida crônica. Resultados e Conclusão: Os resultados foram extraídos das convergências, divergências e idiossincrasias que emergiram das falas dos entrevistados, por meio da análise ideográfica e nomotética. Evidenciou-se que a qualidade de vida do portador de ferida crônica emerge pautada por uma luta constante, permeada por etapas que revelaram a alternância de quadros de melhora e de piora, além de consequências desencadeadas pela ferida que afetaram de maneira negativa a qualidade de vida de portadores de ferida crônica.

Descritores: Feridas e Lesões; Qualidade de Vida; Pesquisa Qualitativa.

\section{ABSTRACT}

Objective: The aim of the research is to understand the quality of life of chronic wound patients. Methods: A qualitative research method in the modality of analysis of the structure of the phenomenon located, which is based on Phenomenology. Results e Conclusion: The data were collected by the researchers through a guiding question directed to ten patients with chronic wound. The results were extracted from the convergences, divergences and idiosyncrasies that emerged from the interviewees'speeches through ideographic and nomothetic analysis and revealed that the quality of life of the chronic wound patient emerges based on a constant struggle permeated by stages that revealed oscillation between improvement and worsening, in addition to consequences triggered by the wound that negatively affected the quality of life of patients with chronic wound.

Descriptors: Wounds and Injuries; Quality of Life; Qualitative Research. 


\section{INTRODUÇÃO}

Em qualquer fase do ciclo vital, pessoas podem ser afetadas pelo desenvolvimento de feridas cutâneas. Todavia, inúmeras feridas se podem tornar crônicas provocando uma série de problemas que afetam a vida do indivíduo em todas as suas esferas, gerando impacto negativo sobre a qualidade de vida $(\mathrm{QV})^{(1)}$. As feridas crônicas são corpos que não agradam, não encantam, não incitam admiração e contemplação. Esses corpos são tratados como "aberrações", além da visão, do tato e do olfato insatisfatórios que provocam ${ }^{(2)}$.

Ao acessar a literatura referente ao tema QV encontramos, ainda que controverso, o conceito de QV mais comumente utilizado por pesquisadores. Baseia-se na própria definição de saúde, da Organização Mundial da Saúde (OMS), ou seja, a percepção individual de um completo bem-estar físico, mental e social(3).

Sob a coordenação de Jonh Orley, o grupo que estuda a QV da OMS, define QV como a percepção do indivíduo de sua posição na vida no contexto da cultura e sistemas de valores, nos quais ele vive e em relação a seus objetivos, expectativas, padrões e preocupações. Nessa equipe pensa-se em, pelo menos, seis domínios de saúde: o físico, o psicológico, o nível de independência, as relações sociais, o meio ambiente e a espiritualidade ${ }^{(4)}$.

Nas pesquisas sociais, os primeiros conceitos de QV confundiam-se com a ideia decorrente de um indicador social, visto que eram descritos tanto fatores ambientais como sociais ligados à qualidade do ar, ao nível socioeconômico e educacional, abordando somente os aspectos objetivos concernentes à qualidade de vida que podem ser mensurados. Porém foi verificado, posteriormente, que nem somente a presença dos aspectos objetivos significava bem estar ou felicidade ${ }^{(5)}$. Sendo assim considerado, observou-se que não são apenas os aspectos objetivos que caracterizam a $\mathrm{QV}$, mas também os subjetivos permeiam a $\mathrm{QV} \mathrm{V}^{(6)}$

A QV vem surgindo como uma nova meta a ser alcançada na área da saúde, já que o principal objetivo do sistema de saúde não pode ser somente a cura e o controle da doença, bem como a prorrogação da morte mas, entre outras intenções, deverá proporcionar melhora da QV das pessoas pertencentes a diferentes contextos sociais( ${ }^{(7)}$. Vale ressaltar que a QV relacionada à saúde (QVRS) é um indicador importante do impacto das doenças crônicas sobre a vida dos indivíduos ${ }^{(8)}$. Na QVRS se reflete a percepção de como uma doença e seu tratamento afetam os aspectos físicos, mentais e sociais da vida ${ }^{(9)}$. Essas percepções fornecem informações bem padronizadas de recuperação, frequência, natureza e são preditores de deficiência, sendo que a QVRS tem sido reconhecida como importante indicador em muitos campos médicos, incluindo os das lesões e das feridas ${ }^{(10)}$.

Os resultados de uma pesquisa realizada com pessoas com doença vascular crônica (DVC) evidenciaram que as pessoas com DVC, com ulceração venosa presente, apresentaram prejuízo significativo na QV, comparadas às pessoas que possuíam DVC, sem a ulceração venosa presente. Os aspectos da QV mais afetados pela presença da úlcera foram considerados: aspecto físico, capacidade funcional, aspectos sociais e saúde física ${ }^{(11)}$.

Em um estudo realizado na Rede de Atenção Básica no município de Natal - RN, identificou-se o comprometimento da QV de pessoas com feridas crônicas, com destaque nas dimensões estado emocional e estética. O tempo de úlcera venosa (UV) atual esteve estatisticamente associado à dimensão estado emocional, utilizado o instrumento Charing Cross Venous Ulcer Questionnaire (CCVUQ), criado e validado em Londres (Reino Unido), para avaliar a QV em pessoas com UV ${ }^{(12)}$.

Por vezes os profissionais de saúde que prestam assistência à pessoa com uma ferida podem não saber que essa lesão pode estar interferindo na sua QV, em sua autoestima e consequentemente prejudicando o seu emocional. No entanto, a QV é considerada construtiva quando favorece a produtividade, o bem estar e a autorealização, mas é destrutiva quando não propicia estes aspectos socioemocionais ${ }^{(13)}$.

Vale ressaltar que a QV é uma noção eminentemente humana, que tem sido aproximada ao grau de satisfação encontrada na vida familiar, amoroso, social, laboral, ambiental e ligada à própria estética com caráter existencial ${ }^{(14)}$.

Assim considerado, é essencial destacar que o paciente com qualquer tipo de ferida deve ser visto como um sujeito que se emociona, que sente, que tem constrangimentos, perda da autoimagem positiva, com suas próprias necessidades. Ao se referir a estes pacientes, é comum algumas colocações que os retraem, tais como as seguintes: "o cliente da úlcera por pressão". Esse tipo de colocação utilizada no decorrer do cuidado produzido é capaz de criar outras feridas, podendo ser mais difíceis de tratar do que aquelas que se manifestam na carne. Tratam-se das "feridas da alma"(2).

Cuidados simples são a limpeza da ferida; cuidados mais avançados passam por oxigenoterapia hiperbárica. Além desses cuidados, a maior parte dos profissionais de saúde pode nem refletir na dimensão metafísica da lesão, que transcende o corpo físico e atinge o corpo imaterial, espiritual, interno. Diferentemente das feridas externas 
(físicas), que podem ser facilmente identificadas, cuidadas e tratadas com produtos, medicamentos e técnicas, a "ferida da alma" muitas vezes não chega a ser identificada, pois é "guardada a sete chaves" pelos pacientes ${ }^{(2)}$.

Não se pode esquecer de que a existência de uma ferida possui força suficiente para desordenar o corpo em sua química e sua emoção. O corpo íntegro tem uma identidade fundamental, ao passo que o corpo com ferida imprime novos sinais e impõe ao sujeito uma nova imagem ${ }^{(2)}$. A imagem do corpo é definida como uma satisfação subjetiva com o corpo de alguém ${ }^{(15)}$. A construção da imagem do corpo é multidimensional e focada no peso, forma e grau ao qual indivíduos estão satisfeitos com a aparência( ${ }^{(16)}$.

Embora existam estudos sobre essa temática, a maioria investiga a imagem corporal em uma amostra de adolescentes e mulheres adultas jovens. Observou-se portanto que a imagem corporal estava associada a comprometimento da QV em relação a alguns aspectos físicos e mentais em mulheres de 18 a $42^{(17)}$. Não foi encontrado nenhum estudo relativo a imagem corporal de portadores de feridas crônicas.

Conjugar uma doença crônica com a QV tem sido um desafio entre os profissionais da saúde, pessoas que vivenciam a doença e seus familiares. Pesquisadores do Núcleo em Situações Crônicas de Saúde referem que mesmo não acontecendo à alteração do quadro da doença, é possível que os indivíduos nessa condição mantenham-se saudáveis, desde que enfrentem os desafios que advém da doença, procurando conciliarem uma relação harmoniosa consigo, com os outros e com o mundo(18).

É indispensável analisar o que a ferida provoca no corpo, uma marca não desejada, que não atinge apenas o domínio do corpo e o domínio psíquico, mas também a família e a equipe de profissionais envolvidos com o paciente. Um sujeito com feridas é como uma tela que sofreu estragos e precisa ser reparada: ele/ela pensa, sente, reage e cria vínculos com a equipe de enfermagem ${ }^{(2)}$.

Diante deste panorama, a proposta deste estudo é compreender a QV do ser portador de ferida crônica.

\section{MÉTODOS}

A Fenomenologia visa compreender o aspecto existencial das nossas vidas, valorizando o conteúdo da experiência em si mesma, donde ser a perspectiva utilizada neste estudo, através da análise da estrutura do fenômeno situado, de acordo com Martins e Bicudo ${ }^{(19)}$. Essa abordagem qualitativa foi descrita por Edmund Husserl (1859-1938), na Alemanha, como uma alternativa na busca do conhecimento, considerando o método experimental pouco adequado para tratar as questões do ser humano e de seu mundo vivido.

Nessa abordagem, a partir da reflexão de experiências vividas por portadores de ferida crônica foram estes a qualificar suas vidas. Vemos neste método uma possibilidade de ir ao encontro do fenômeno QV de portadores de feridas crônicas ${ }^{(19)}$.

Vale ressaltar que Martin Heidegger (1889-1976) faz uma redefinição da Fenomenologia, caracterizando-a como um método que não procura "o quê" do objeto de estudo, mas "como" se mostra esse objeto a partir de si mesmo, como experiência no mundo. Para este fenomenólogo, ser-no-mundo relaciona-se com três níveis de análise: o ambiente, ou o mundo ao redor; as relações ou o mundo com os semelhantes; e o interior, ou o mundo consigo mesmo, sendo que estes níveis dão forma à existência da mulher e do homem ${ }^{(20)}$.

Portanto, pretendemos através da fenomenologia heideggeriana, ver o humano através dele próprio, visando compreender a QV daquele que é portador de ferida crônica. Desta forma, situamos o fenômeno investigado nesta pesquisa em pessoas que vivenciam o momento de serem portadoras de ferida crônica, na tentativa de vislumbrar a qualidade de suas vidas.

Os dados desta pesquisa estão apresentados através das descrições de relatos de portadores de feridas crônicas. Com o propósito de buscar um contexto onde o fenômeno pudesse ser inquerido, escolhemos uma Clínica de Enfermagem, de uma Instituição de Ensino Superior, do interior do Estado de São Paulo. Para obtenção destes relatos entramos em contato com pessoas portadoras de ferida crônica, cadastradas nesta Clínica de Enfermagem, em seus domicílios. O número de sujeitos foi determinado pelo surgimento de convergências nos discursos.

Foi obtida a aprovação pelo Comitê de Ética e Pesquisa, da UFMS, sob o parecer $n^{\circ} 784.679$, com assinatura do consentimento livre e esclarecido, elaborado de acordo com a Resolução 466/12, daqueles que concordaram em participar do estudo.

Os discursos foram obtidos a partir da seguinte questão norteadora: "Como é para você ser portador de ferida crônica?" 
Para a análise dos discursos de pessoas que são portadores de feridas crônicas seguimos as operações propostas por Martins e Bicudo. Desta forma a análise foi efetuada em dois momentos: a análise ideográfica e a análise nomotética.

Para a análise ideográfica, que consiste na análise individualizada dos discursos, procedemos como se segue: fizemos a transcrição na integra do discurso, realizamos várias leituras (a fim de nos familiarizarmos como o discurso), identificamos as unidades de significado e analisamos as convergências e divergências internas.

Terminada a análise individualizada dos discursos efetuamos um movimento em direção à generalidade dos discursos, através da análise nomotética. Nesta análise identificamos as convergências, divergências e idiossincrasias entre as unidades de significados de todos os discursos ${ }^{(7)}$.

\section{RESULTADOS E DISCUSSÃO}

Foram utilizados 10 discursos de portadores de feridas crônicas, transcritos na íntegra, buscando manter a sua fala originária. Posteriormente foram extraídas as unidades de significados, enumeradas no próprio discurso e em seguida interpretadas, transformando-as em conteúdo mais compreensivo, mostrando estruturas que pareciam ocultas, como se exemplifica, por meio da apresentação de um dos discursos. Os números que seguem as falas referem-se à sua introdução no Quadro I.

"Eu descobri que tinha diabete eu tinha 38 anos só que eu não cuidei, eu não estava nem aí. Quando eu descobri eu estava com 120. Nem era considerado diabetes mais o médico mandou toma cuidado né? Ai comia doce, eu fazia tudo que tinha direito. Quando eu fui perceber, começou a dar problema nas vistas, começou é a dar falta de ar, sabe? Ai foi ver já estava 480. Eu tava com problema no coração. Ai eu comecei a tratar com cardiologista de Jales. Ai ele foi e fez todos os exames, né? Tudo. Aí eu comecei a tomar insulina que eu não tomava. Hoje eu tomo insulina e ela está controlada. Hoje é 80 - 90 toda vez. Eu tenho o aparelho de olha em casa, tem aparelho de pressão, tenho tudo. Tinha pressão alta. Sá que agora hoje eu faço tudo certinho. Não como doce, não como massa. Só depois que já estragou tudo as vista e eu já estou quase cega também. Mas assim agora a ferida me incomoda, me incomoda por causa do sapato. Tenho vontade de usar um sapato bonitinho que nem todo mundo usa e não posso porque tenho que usar essa porcaria de sapatos feios. Então tudo isso me incomoda, única coisa que me incomoda às vezes. Eu falo e as pessoas ficam bravas. É o pé machucado, é a única coisa que me incomoda. Quando eu mudei pra cá me deu depressão sabe, nossa eu queria sumir, eu tinha até colocado uma troca de roupa dentro de uma sacola pra ir embora e não sabia pra onde ia. Eu falei que ia pegar uma carona. Eu pensava na minha cabaça, eu trancava a porta e os outros tocava a companhia e eu não atendia, as pessoas pensavam até que eu não estava em casa. Eu pensei em pegar uma carona com caminhão que fica ali no posto - vou vazar pro Mato Grosso, sem um centavo. Eu não tinha um centavo. Ai eu fiquei. Eu não dormi, não comia, emagreci $17 \mathrm{Kg}$. Eu pesava $97 \mathrm{Kg}$ e emagreci. Pra mim também foi uma boa, porque eu era gorda, desmazelada, relaxada, cabelo branco. Não me cuidava. As meninas ficavam bravas. Eu não estava nem aí. Depois que eu mudei, que comecei - que um cara, um locutor de Jales que mudou a minha vida, ligando no programa dele. E eu comecei a conversar com ele. E ele muito alegre me tratou muito bem. E eu achei que eu estava viva. Aí eu mudei, aí mudei tudo, tudo. Só o pé é que não tem condição de mudar, porque não tem jeito, porque não tem um calçado que possa usar, que tem esperar sarar. Mas o cara garantiu pra mim lá na faculdade, que sara. O enfermeiro falou que vai sarar, a enfermeira falou que sara, que tem cura. É demorado mais tem cura. Pra quem queria corta o pé, o médico queria amputar meu pé. Então quer dizer que, ela achou que até está evoluindo rápido. Diminuiu uns 3 centímetros a ferida, depois que começou a tirar aquelas pele amarela. Parece que chama queratina. É uma pele morta. Começou a tirar. Aí a carne já está crescendo já, já está fechando aquele buraco, aquela ferida, está diminuindo toda semana que eles cortam. Graças a Deus, está melhorando bem, não tem cheiro. A ferida é vermelhinha. Não tem odor. Então eu falo assim: se Deus quiser vai sarar sim. Vou ter paciência. É a única coisa que me incomoda é essa ferida, ela me incomoda. Já vai fazer 3 anos agora dia 14 de fevereiro. Foi o dia que ele fez a cirurgia no meu pé, vai fazer 3 anos. A cirurgia foi feita porque parecia que eu tinha pisado na brasa. Ele mesmo falou pra mim: você queimou seu pé. Doutor eu não ando descalço, eu não consigo pisar no chão. Doía a sola do pé, eu não queimei. Estouro essas bolhas de água, parecia bexiga d'água. Em vez de ele pegar e só estourar, que nem o médico fez depois que estourou as outras, só tirou, estourou, limpou, fez o curativo. Não ele arrancou, ficou assim no nervo lá no fundo aquele buracão. Aí foi fechando, fico essa ferida aí ainda mais na sola do pé. Não tem condição, fico o dia inteirinho deitado, não aguento também. Você acha lugar que ando a pé? É só dentro da garagem, só saio de carro. Parei de fumar há 29 anos, bebo uma cervejinha de vez em quando, que eu e meu filho saímos, gosto de passear..." (Discurso III) 


\begin{tabular}{|c|c|}
\hline Fala do Entrevistado & Linguagem das Pesquisadoras \\
\hline $\begin{array}{l}\text { 1. Descobri que tinha diabete eu } \\
\text { tinha } 38 \text { anos só que eu não cuidei } \\
\text { eu não estava nem ai. }\end{array}$ & $\begin{array}{l}\text { 1. Ela descobriu que tinha diabetes } \\
\text { aos } 38 \text { anos, porém não cuidou, ela } \\
\text { não ligava. }\end{array}$ \\
\hline 2. Agora a ferida me incomoda. & 2. Agora a ferida a incomoda. \\
\hline $\begin{array}{l}\text { 3. Me incomoda por causa do } \\
\text { sapato, tenho vontade de usar } \\
\text { um sapato bonitinho que nem todo } \\
\text { mundo usa e não posso porque } \\
\text { tenho que usar essa porcaria de } \\
\text { sapatos feios então tudo isso me } \\
\text { incomoda. }\end{array}$ & $\begin{array}{l}\text { 3. Incomoda-a por causa do sapato. } \\
\text { Ela tem vontade de usar um sapato } \\
\text { bonitinho que nem todo mundo usa e } \\
\text { não pode, porque tem que usar essa } \\
\text { porcaria de sapatos feios. Então } \\
\text { tudo isso incomoda ela. }\end{array}$ \\
\hline
\end{tabular}

4. Única coisa que me incomoda as vezes é o pé machucado.

4. A única coisa que a incomoda, às vezes, é o pé machucado.

5. É a única coisa que me 5. É a única coisa que a incomoda. incomoda.

6. Me deu depressão, sabe? Nossa 6. Ela deprimiu-se e queria sumir. eu queria sumir.

7. Eu tinha até colocado uma troca 7. Ela tinha até colocado uma troca de roupa dentro de uma sacola pra de roupa dentro de uma sacola para ir embora e não sabia pra onde ia. ir embora e não sabia para onde Eu falei que ia pegar uma carona.

8. Eu trancava a porta e os outros tocavam a companhia e eu não atendia.

9. Eu pensei em pegar uma carona com caminhão, que fica ali no posto. Vou vazar pro Mato Grosso, sem um centavo. Eu não tinha um centavo. Aí eu fiquei.

10. Eu não dormi.

11. Não comia, emagreci $17 \mathrm{Kg}$, eu pesava $97 \mathrm{Kg}$.

12. E emagrecer - pra mim também foi uma boa, porque eu era gorda

13. Um locutor de Jales, que mudou a minha vida. Ligando no programa dele, eu comecei a conversar com ele. $\mathrm{E}$ ele, muito alegre, me tratou muito bem. E eu achei que eu estava viva. Ai eu mudei, ai mudei tudo, tudo. Só o pé é que não tem condição de mudar

14. Não tem jeito, porque não tem um calçado que possa usar.

15. Lá na faculdade que sara, o enfermeiro falou que vai sarar. A enfermeira falou que sara, que tem cura. É demorado mais tem cura.

16. Pra quem queria cortar o pé. O médico queria amputar meu pé. pé
3. Ela deprimiu-se e queria sumir.

4. Ela pensou em ir embora e não sabia para onde iria. Pensou em pegar uma carona com caminhão, que fica ali no posto e fugir para o Mato Grosso, sem um centavo. Por isso ela ficou.

8. Ela trancava a porta e a campainha 5. Ela trancava a porta e a campainha tocava e ela não atendia.

8.

$11,12$. ela pesava $97 \mathrm{Kg}$. Emagrecer foi bom, porque ela era gorda.

12. Emagrecer para ela foi bom, porque ela era gorda.

13. Um locutor de Jales é que mudou 8 . Um locutor de Jales é que mudou a sua vida. Ligando para o programa a vida dela. Ligando para o programa dele, ela começou a conversar com dele, ela começou a conversar com ele, que era muito alegre e a tratou ele, que era muito alegre e a tratou muito bem. E ela achou que estava muito bem. E ela achou que estava viva e mudou tudo. Só o pé é que viva e mudou tudo. Só o pé é que não não tem condição de mudar.

14. Não tem condição de mudar o pé, porque não tem um calçado que possa usar.

9. Não tem condição de mudar o pé, porque não tem um calçado que possa usar.

15. Na faculdade que sara, o 10. Na faculdade que sara, o enfermeiro falou que vai sarar. A enfermeiro falou que vai sarar. A enfermeira falou que sara, que tem enfermeira falou que sara, que tem cura. É demorado mas tem cura. cura. É demorado mas tem cura.

16. O médico queria amputar meu 11 . O médico queria amputar meu pé. 
17. Ela achou que até ta evoluindo 17. A enfermeira achou que até 12 . A enfermeira achou que até está rápido. Diminuiu uns 3 centímetros está evoluindo com rapidez, pois a evoluindo com rapidez, pois diminuiu a ferida. Depois que começou a ferida diminuiu uns 3 centímetros, tirar aquelas pele amarela, parece desde que começou a tirar aquela que chama queratina. É uma pele morta, começou a tirar. Ai a carne já ta crescendo já, já ta fechando aquele buraco, aquela ferida ta diminuindo, toda semana que eles cortam. Graças a Deus ta melhorando bem, não tem cheiro, a ferida é vermelhinha, não tem odor.

18. Se Deus quiser vai sarar sim.

19. Vou ter paciência.

20. É a única coisa que me incomoda, é essa ferida.

21. Ela me incomoda.

22. Já vai fazer 3 anos agora dia 14 de fevereiro.

23. Eu não ando descalça. pele amarela, parece que chama queratina. É uma pele morta, começou a tirá-la. A carne já está crescendo, está fechando aquela ferida, está diminuindo, toda a semana em que eles a cortam. Graças a Deus está melhorando bem, não tem cheiro, a ferida é vermelhinha, não tem odor.

18. Se Deus quiser, vai sarar.

19. Ela vai ter paciência.

20. A única coisa que a incomoda é essa ferida.

21. A ferida a incomoda.

22. No dia 14 de fevereiro, vai fazer 3 anos que tem a ferida.

23. Ela não anda descalça. uns 3 centímetros a ferida, desde que começou a tirar aquela pele amarela parece que chama queratina. É uma pele morta, começou a tirar. A carne já está crescendo, está fechando aquela ferida, está diminuindo, toda semana que eles a cortam. Graças a Deus está melhorando bem, não tem cheiro, a ferida é vermelhinha, não tem odor.

13. Se Deus quiser, vai sarar.

14. Ela vai ter paciência.

15. No dia 14 de fevereiro, vai fazer 3 anos que tem a ferida.

16. Ela não anda descalça, não

18.

19. consegue pisar o chão, pois tem dor na planta do pé. Não tem condição de andar e fica o dia inteiro deitada, não aguenta.

$23,24,25$

24. Ela não consegue pisar no chão, pois tem dor na planta do pé e ela não o queimou.

24. Eu não consigo pisar no chão. Doía a sola do pé. Eu não queimei.

25. Não tem condição. Fica o dia inteirinho deitado não aguento também... você acha...

25. Não tem condição de andar e fica o dia inteiro deitada, porque não aguenta.

26. Lugar que ando a pé é só 26. Somente anda a pé dentro da dentro da garagem só, saio de carro

17. Somente anda a pé dentro da garagem, de onde só sai de carro.
17.

\section{Análise Nomotética - Estrutura do Fenômeno Ser Portador de Ferida Crônica}

Depois da análise ideográfica, realizamos a análise nomotética, em que buscamos as generalidades que configuram os significados dados pelos portadores de feridas crônicas às suas experiências, qualificando suas vidas. Agrupamos as unidades de significado em categorias amplificadas, convergidas, originadas da análise prévia. Nessa fase começamos a desvendar a estrutura do fenômeno - ser portador de ferida crônica.

As convergências dos discursos de alguns entrevistados levaram as pesquisadoras a criarem uma categoria denominada "luta", em virtude de diversos portadores de ferida crônica mencionar esta luta, como uma característica presente no cotidiano dos mesmos, conforme evidenciado nos seguintes discursos:

Ela lutou bastante. Foi nos médicos, passou por consulta... (Discurso II - 3)

Ela está lutando faz tempo até os dias de hoje. (Discurso II- 26)

É um tipo de pessoa que enfrenta a situação. Já tem mais de vinte anos que ela vem lutando com isso. (Discurso V - 4)

Na fala de certos entrevistados emergiu uma nova categoria - "etapas da vida de um portador de ferida crônica e suas consequências", revelando que a ferida apresenta um quadro de melhora e de piora, em alternâncias. Também se identificam consequências desencadeadas pelas feridas, que afetaram significativamente a QV, de acordo com os discursos abaixo mencionados:

Apresenta períodos de melhora e piora em alternância... (Discurso I - 6)

Depois ocorreu flebite e ela acha que tudo isso atrapalhou. (Discurso II - 6)

Já pegou bicho duas vezes e foi até a clínica e eles tiraram mais de quatrocentos bichos. (Discurso VI - 30) 
Diferentes locais e maneiras de tratar a ferida crônica emergiram nos discursos dos entrevistados, culminando em uma das categorias denominada "tratamento da ferida", conforme explicitado como segue:

Faz os curativos sozinha em casa. Antes frequentava a clínica, não vai no postinho. (Discurso $X$ - 20) O curativo era feito nas unidades básicas de saúde, depois na Clínica de Enfermagem. (Discurso IV - 6)

Ela procura a rede pública e tem sido muito bem atendida. (Discurso $V$ - 6)

A categoria "história da ferida" salienta-se, na medida em que os entrevistados fazem questão de relatar como surgiu a ferida, evidenciado nos seguintes discursos:

O médico diagnosticou como uma ulcera varicosa. (Discurso II - 5)

A doença apareceu há 7 anos atrás. (Discurso VI - 2)

As falas de alguns entrevistados conduziram à criação da categoria "fé em Deus e a esperança de sarar", revelando expectativas positivas frente a vida, bem como crenças religiosas adquiridas nas suas trajetórias de vida, de acordo com os discursos abaixo identificados:

As pessoas falam muitas coisas para ela referente a ferida. Por isso roga a Deus. E ressalta que tem que aguentar muitas conversas. (Discurso II - 24)

Acredita que vai sarar, tem fé em Deus. Se ele quiser, vai sarar. (Discurso I - 21)

Se Deus quiser, vai sarar, sim. (Discurso III - 13)

Também emergiu nas falas dos entrevistados a categoria "sentimentos negativos e depressão", o que permeia seus cotidianos, revelado nas falas a seguir sublinhadas:

Só que muitas vezes elas se chocam [sentimento negativo]. (Discurso $V$ - 19)

Teve depressão e queria sumir. (Discurso III - 3)

No começo teve depressão, por causa da ferida. (Discurso VI - 8)

Tem vergonha [sentimento negativo] de ficar na comunidade. (Discurso VI - 26)

De acordo com os discursos, se cria a ilação de que seja de valor "o apoio e a compreensão" (uma outra categoria). Outros aparecem na vida do portador de ferida crônica, proveniente de famílias, de equipes de saúde, da igreja professada, de patroas nos seus empregos, conforme as falas abaixo:

Tira o chapéu para a equipe de enfermagem, porque ela não dá conta de fazer o curativo sozinha. (Discurso $V$ - 17)

As patroas esperavam ela sarar, pois gostavam muito dela... (Discurso $X$ - 8)

Ela frequentava a igreja e era a coisa que ela mais gostava- Agora solicita aos filhos que a levem para a igreja e na casa da mãe. (Discurso I - 14)

A noção que conduz à categoria de "invalidez e dependência" de outras pessoas também aparecem no cotidiano dos portadores de ferida crônica, uma vez que muitos dos entrevistados relatam se sentirem inválidos e não autónomos no seu circulo social, o que se explicita da seguinte forma:

Fazem 2 anos que ela esta afastada. (Discurso I - 16)

O serviço de casa não faz, mas os filhos tentam ajudá-la. (Discurso I - 22)

Ela se sente inválida e é a sua maior tristeza. Quer fazer o serviço de casa, mas não consegue. (Discurso I - 10)

A categoria "preconceito" sugere-se a partir do relatado pelos entrevistados. Esse juízo preconcebido aparece como uma situação convergente na trajetória de vida do portador de ferida crônica: Porém também aparece como uma divergência apenas no discurso de um dos entrevistados, conforme evidenciado a seguir:

Os postos de saúde estão o discriminando, ao pedir material para fazer os curativos... (Discurso VI - 12)

O povo foi-se desligando de mim, por causa desse problema meu. A sociedade começou a ignorá-lo. (Discurso $\mathrm{VI}-4)$ 
Ele não sente nenhum tipo de preconceito. (Discurso VII - 12)

De acordo com os discursos podemos a categoria "dor e incômodos diversos", uma constante na vida dos portadores de ferida crônica, que relatam sentir horas de dor e se incomodam com o aspecto, cheiro, coceira e secreções da ferida, como relacionado a seguir:

Tem dor 24 horas, dia e noite. (Discurso VI - 3)

Com a mudança do tempo dói demais. (Discurso VII - 8)

Ficava muito incomodada com o cheiro, com a dor e com a coceira. (Discurso IX - 2)

As falas de alguns entrevistados apontam o que se designa na categoria "estratégias de enfrentamento", tais como burlar algumas situações, falar das suas dores, se cuidar e optar por calças compridas, conforme os discursos abaixo:

Ela vai ter paciência. (Discurso III- 14)

Tem dia que quer enganar as pessoas e coloca um calça cumprida. (Discurso VII - 5)

Agora ela está tentando se cuidar, ela se cuida. (Discurso V- 34)

Ela vai burlando as coisas, ela coloca uma meia quando pode. Vai mascarando, ao invés de sair com uma saia curta, ela coloca uma longa. Foi obrigada a encontrar atalhos para não chocar as pessoas. (Discurso V - 27)

Podemos considerar ainda a categoria "risco de amputação", que aparece nas falas de diversos entrevistados, que relatam situações de médicos e de outras pessoas que os alertam quanto a essa possibilidade e a dificuldade daqueles que passaram por esse procedimento, conforme abaixo se refere:

Ela já enfrentou pessoas chegando na sua casa e falando: "você não tem medo de ter que amputar seu pé?" (Discurso V - 5)

Deitar numa cama com o pé e sair sem ele é difícil. (Discurso IV - 16)

O médico queria cortar a perna dele no joelho. (Discurso IV - 4)

"Dificuldades e desejos não correspondidos" (categoria) inclui o revelado nos discursos dos portadores de ferida crônica, de acordo com os discursos evidenciados a seguir:

Tem desejo de querer ter alguém, de andar e não poder. (Discurso VII - 18)

A pomada, quando usa, vai quase 2 tubos cada vez. Não tem condição de pagar. Então somente limpa a ferida sem passar nada. Não tem condições de ficar comprando e de pagar consulta médica. (Discurso VI - 15)

A categoria "filhos" refere-se à sua importância para o portador de ferida crônica. Aparece nos discursos de dois dos entrevistados, mostrando que o amor pelos filhos pode trazer felicidade, conforme evidenciado abaixo:

Seus filhos são a coisa mais gostosa do mundo, são um tesouro... (Discurso VIII - 18)

Seus filhos são a sua felicidade. (Discurso I - 23)

Também aparece como elementos convergentes a categoria "mudança de vida" dos portadores de ferida crônica. Nota-se nos discursos abaixo identificados que as limitações que a ferida impõe conduzem a transformações, muitas vezes bastante significativas.

Não é muito bom ter estas feridas, porque não tem como sair de casa. (Discurso VII - 5)

A sua vida mudou muito, ou seja, completamente. (Discurso VII - 11)

Mudou tudo em sua vida, sua atividade toda. (Discurso IV - 8)

Apenas uma das entrevistadas mencionou a condição de "fuga" (categoria residual), como uma reação diante da situação de ser uma portadora de ferida crônica, conforme abaixo:

Pensou em pegar uma carona com um caminhão que fica no posto e fugir (Discurso III - 4)

A categoria "internação" justifica-se, pensando em instituição hospitalar e que faz parte da vida de portadores de ferida crônica, que ocasionalmente necessitam deste tipo de intervenção, conforme as seguintes falas: 
Após a internação, é a mesma vida. (Discurso II - 13)

Ele ficou 15 dias internado em hospital. (Discurso IV - 3)

Por sua vez, a categoria "recomendação de outras pessoas" emerge nos discursos dos entrevistados, como se expõe a seguir:

Como inhame, pêssego, vários tipos de frutas, porque falam que é bom para cicatrizar... (Discurso VII - 13)

Tudo que os outros ensinam ela faz. (Discurso II - 29)

Por último, observou-se condição, agregada na categoria "não andar ou andar com dificuldade", que faz parte do cotidiano de diversos dos portadores de ferida crônica, em virtude das limitações físicas geralmente vinculada à dor.

Quando piorou muito, ela passou a não andar mais. (Discurso IX - 4)

Ela não pode andar. (Discurso I - 11)

...não aguenta andar muito, pois sente muita dor. (Discurso II - 10)

\section{CONSIDERAÇÕES FINAIS}

De acordo com as convergências evidenciadas, com uma divergência e uma idiossincrasia, se colocam discursos dos entrevistados. O significado de ser portador de ferida crônica emerge como uma "luta" constante no cotidiano dos mesmos. Também ficou claro que existem "etapas na vida" destes portadores, com quadros de melhora e piora em alternância. É de realçar as consequências desencadeadas pela ferida, que afetaram significativamente a QV, tais como as seguintes: emagrecer, "pegar bicho", não dormir, entre outros sinais e sintomas.

$\mathrm{O}$ "tratamento da ferida" faz igualmente parte da sua QV, mostrado com detalhes referentes ao local de tratamento, à maneira de se tratar a ferida e ao sujeito que realizava os curativos.

Detecta-se que os participantes fazem questão de relatar como foi que a ferida surgiu, ou seja, como foi a "história da ferida".

Acresce dizer que a "fé em Deus e a esperança de sarar" revelam expectativas positivas de QV. "Sentimentos negativos e depressão" também permeiam essa condição (QV). Porém, "o apoio e a compreensão" proveniente de familiares, equipes de saúde, membros da igreja, patroas e de outros enquadra, de maneira significativa, a experiência dos portadores de ferida crônica.

"A invalidez e a dependência" de pessoas aparecem qualificando a vida no seu círculo social. O "preconceito" é frequente no grupo de estudo, embora exista uma divergência na fala de apenas um dos entrevistados que relata não sentir nenhum tipo de preconceito.

"A dor e o incômodo" como aspecto a salientar, incluindo o cheiro, a coceira e as secreções da ferida, aparecem interferindo na $\mathrm{QV}$ desses pacientes.

Por sua vez, "as estratégias de enfrentamento" por parte dos portadores de ferida crônica passam por burlar algumas situações, falar das suas dores, se cuidar e optar por usar calças compridas.

O "risco de amputação" se evidencia em diversos momentos da vida, ou seja, se ouve de médicos e de outros. Estão alertando quanto à possibilidade deste procedimento ocorrer.

Assim colocado, também diversas "dificuldades e riscos não correspondidos" são esclarecidos. Porém, o amor pelos "filhos" aparece como um fator que pode trazer felicidade. Certos entrevistados se referem a "mudança de vida" proveniente das limitações que a ferida impõe.

Apenas uma das entrevistadas mencionou, como foi dito, a "fuga" diante da situação de ser portadora de ferida crônica, caracterizando uma idiossincrasia.

A "internação" em instituição hospitalar constante, as "recomendações de outros" e "não andar ou andar com dificuldade" fazem parte da QV dos portadores de ferida crônica. A última categoria é geralmente vinculada à dor que a ferida crônica impõe a este grupo de pacientes.

Diante desse panorama, acreditamos que esta pesquisa possa contribuir para a compreensão do que é vir a ser portador de ferida crônica. Sendo que a abordagem qualitativa por meio do Fenômeno Situado proporcionou extrair aspectos subjetivos da vida do grupo estudado, proporciona subsídios para que possamos compreender o impacto negativo na $Q V$ de portadores de ferida crônica e consequentemente ocorrer uma assistência mais autêntica prestada a estas pessoas pelos profissionais de saúde. 


\section{REFERENCIAS}

1. Yamada BFA. Santos VLCG. Construção e Validação do Índice de Qualidade de Vida de Ferrans \& Powers Versão Feridas. Rev Esc Enferm USP 2009; 43(Esp):1105-13.

2. Silva RCL, Figueiredo NMA, Meireles IB.Feridas: fundamentos e atualizações em enfermagem. 3 ed. São Caetano do Sul, SP: Yendis Editora, 2011.

3. Ferraz MB. Qualidade de Vida - conceito e um breve histórico. Jovem Méd 1998; 3(4):219-22.

4. The Whoqol Group. The World Health Organization Quality of Life Assessment (WHOQOL): position paper from the World Health Organization . Soc Sci Med 1995; 41:1403- 9.

5. Flanagan JC. Measurement of quality of life: current state of the art. Arch Phys Med Rehabil 1982; 63(2):56-9.

6. Marchi R, Silva MAD. Saúde e qualidade de vida no trabalho. São Paulo: Best Seller; 1997.

7. Nordenfelt L, editor. Concepts and measurement of quality of life in health care. Boston: Kluwer Academic; 1994. Introduction; p. 1-15.

8. Vasconcelos AG, Haase VG, Lima EP, Lana-peixoto MA. Mantendo a qualidade de vida na esclerose múltipla: fato, ficção ou realidade circunscrita?. Arq. Neuro-Psiquiatr. 2010; 68(5): 726-730.

9. Cnossen MC et al. Comparing health-related quality of life of Dutch and Chinese patients with traumatic brain injury: do cultural differences play a role? Health and Quality of Life Outcomes. 2017; 15:72.

10. Neugebauer E, Bouillon B, Bullinger M, Wood-Dauphinee S. Quality of life after multiple trauma-summary and recommendations of the consensus conference. Restor Neurol Neurosci. 2002; 20:161-7.

11. Dias TTAF, Costa IKF, Melo MDM, Torres SMSGSO, Maia EMC, Torres GV. Avaliação da qualidade de vida de pacientes com e sem úlcera venosa. Rev. Latino-Am. Enfermagem. 2014; 22(4):576-581.

12. Araújo RO, Silva DC, Souto RQ, Pergola-Marconato AM, Costa IKF, Torres GV. Impacto de úlceras venosas na qualidade de vida de indivíduos atendidos na atenção primária. Aquichan.2016;16(1):56-66.

13. Marinho, B. Qualidade de vida: necessidade ou modismo? Rev. Insight-Psicoterapia, v. 1992; 23:26-28.

14. Minayo SCS, Hartz, ZMA, Buss PM. Qualidade de vida e saúde: um debate necessário. Ciência \& Saúde Coletiva. 2000; 5(1):7-18.

15. Alipour B, Farhangi MA, Dehghan P, Alipour M.Body image perceptions and its association with body mass index and nutrient intakes among female college students aged 18-35 years from Tabriz,Iran. Eat Weight Disord. 2015;20:465-471.

16. Peat CM, Peyerl NL, Muehlenkamp JJ. Body image and eating disorders in older adults: a review. Journal of General Psycholog. 2015; 35:343-358.

17. Mond J, Mitchison D, Latner J, Hay P, Owen C, Rodgers B. Quality of life impairment associated with body dissatisfaction in general population sample of women. BMC Public Health. 2013; 13(920):1-11.

18. Silva DMGV, Vieira RM, Koschnik Z, Azevedo, M, Souza, SS. Qualidade de vida de pessoas com insuficiências renal crônica em tratamento hemodialítico. Rev Bras Enf,. 2002; 55(5):562-567.

19. Martins J, Bicudo MAV. A pesquisa qualitativa em psicologia: fundamentos e recursos básico. São Paulo: Moraes/ EDUC, 1989.

20. Heidegger M. Ser e Tempo: Parte I. 5.ed. Petrópolis: Vozes, 1995.

\section{Endereço para correspondência:}

Patrícia Moita Garcia Kawakame

Av. Costa e Silva s/n

Bairro Universitário

CEP: 79070-900 - Fernandópolis - SP - Brasil

E-mail: patriciamoita.ufms@gmail.com 